- SAND94-8206 - UC-402

Unlimited Release

Printed December 1993

\title{
Process Waste Assessment for Inorganic Solid Waste and Empty Containers $<30$ Gallons
}

N. M. Phillips

Prepared by

Sandia National Laboratories

Albuc Horeug Now Mexico 87185 and Ltvormore, Califomia 94551

for the Unitod States Department of Energy

under Contract DE-AC04-94AL.85000

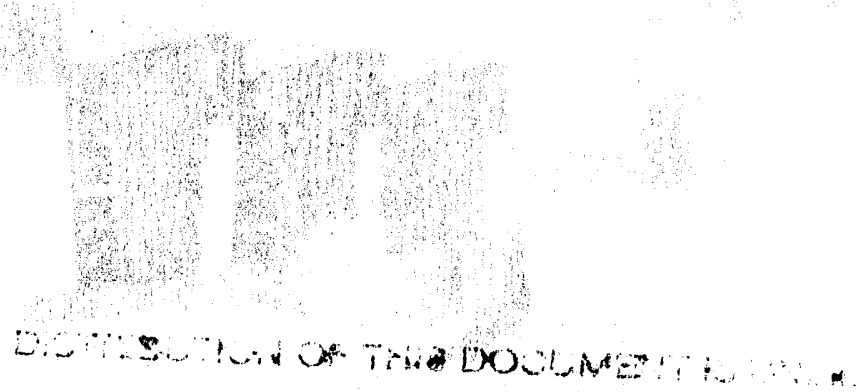


Issued by Sandla National Laboratories, operated for the United States Department of Energy by Sandla Corporation.

NOTICE: This report was prepared as an account of work sponsored by an agency of the United States Government. Neither the United States Government nor any agency thereof, nor any of their employees, nor any of the contractors, subcontractors, or their employees, makes any warranty, express or implied, or assumes any legal liability or responsibility for the accuracy, completeness, or usefulness of any information, apparatus, product, or process disclosed, or represents that its use would not infringe privately owned rights. Reference herein to any specific commercial product, process, or service by trade name, trademark, manufacturer, or otherwise, does not necessarily constitute or Imply its endorsement, recommendation, or favoring by the United States Government, any agency thereof or any of their contractors or subconractors. The views and opinions expressed herein do not necessarily state or reflect those of the United States Government, any agency thereof or any of their contractors or subcontractors.

This report has been reproduced from the best available copy.

Available to DOE and DOE contractors from:

Office of Scientific and Technical Information

P.O. Box 62

Oak Ridge TN 37831

Prices available from (615) 576-8401, FTS 626-8401.

Available to the public from:

National Technical Information Service

U.S. Department of Commerce

5285 Port Royal Rd.

Springfield, VA 22161 
SAND94-8206

Unlimited Release

Printed December 1993

\title{
PROCESS WASTE ASSESSMENT \\ FOR \\ INORGANIC SOLID WASTE AND \\ EMPTY CONTAINERS <30 GALLONS
}

\section{Norman M. Phillips}

Sandia National Laboratories/California

\begin{abstract}
This Process Waste Assessment was conducted to evaluate the two largest hazardous waste streams generated on-site at SNL/California- "Other Inorganic Solid Waste" and "Empty Containers $<30$ Gallons."

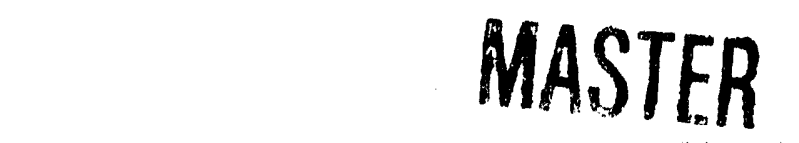

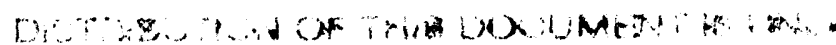




\section{ACKNOWLEDGMENTS}

The author would like to thank the following Environmental Protection Department personnel for their significant contributions to this report: Kim Shepodd, Dick McMaster, Kevin Lloyd, Ed Dolstra, and Rodney Garcia. 


\section{CONTENTS}

\section{Page}

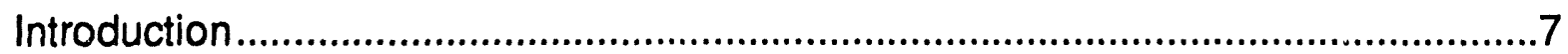

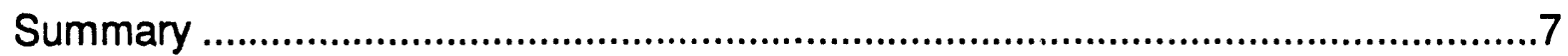

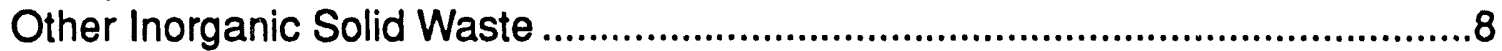

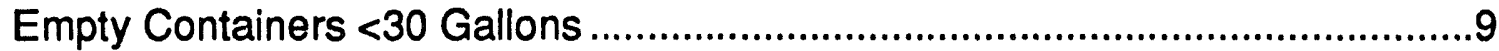

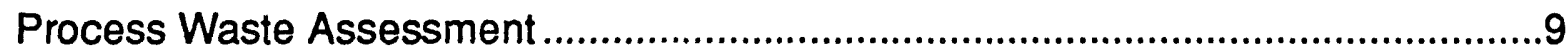

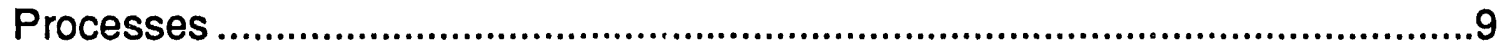

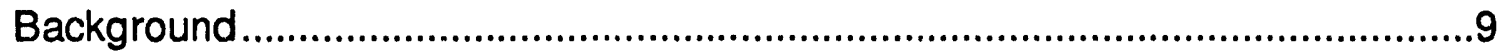

Waste Characterization and Generation ......................................................10

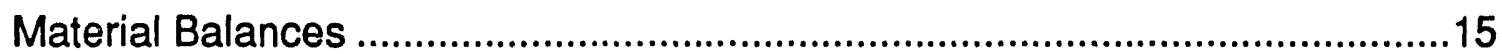

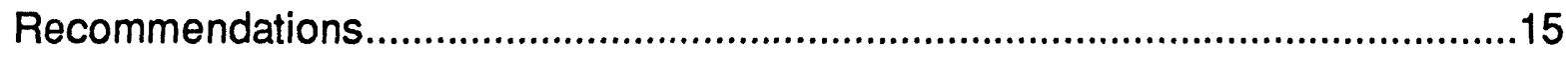

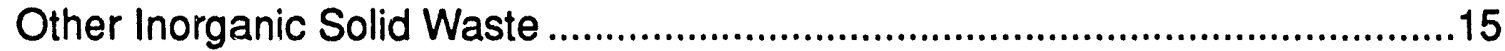

Empty Containers $<30$ Gallons ....................................................................16

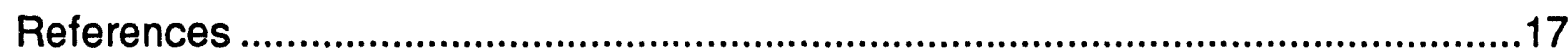

\section{ILLUSTRATIONS AND TABLES}

No.

Fig. 1 Site process flow for "Other Inorganic Solid Waste" and "Empty Containers <30 Gallons".

Fig. 2 "Other Inorganic Solid Waste" flow diagram..........................................12

Fig. 3 "Empty Containers <30 Gallons" flow diagram......................................14

Table 1 Major Constituents of the "Other Inorganic Solid Waste" Stream, Generated at SNL/California from January 1990 to July 1993

Table 2 Amount of the "Empty Containers $<30$ Gallons" Waste Stream Generated at SNL/California from January 1990 to July 1993. 


\section{PROCESS WASTE ASSESSMENT INORGANIC SOLID WASTE AND EMPTY CONTAINERS $<30$ GALLONS}

\section{Introduction}

SNL/California has developed a Waste Minimization Program in accordance with the requirements of DOE Orders 5400.1 and 5400.3.1,2 This program's goals are:

1. to reduce the volume and toxicity of hazardous wastes generated on-site,

2. to implement a system of tracking and reporting improvements, and

3. to devise a method for performing assessment and minimization tasks.

To satisfy the requirements of this program, process waste assessments (PWAs) are conducted to identify waste-generating processes. The information collected from PWAs is used to identify waste minimization opportunities.

This PWA was conducted a little differently than other PWAs. Normally, PWAs are conducted on a specific process that generates hazardous wastes. However, this PWA evaluates waste streams generated by a number of processes because the two waste streams listed were identified as processes in the Source Reduction Evaluation Review And Plan (SRERP). ${ }^{3}$ Therefore, they should be characterized through a PWA.

The waste streams assessed for this PWA were "Other Inorganic Solid Waste" and "Empty Containers $<30$ Gallons." The PWA was conducted according to the revised Sandia Process Waste Assessment Plan (June 1993). ${ }^{4}$ The PWA has two main purposes:

1. establish a baseline for these two waste streams and

2. encourage generators to participate in reducing the volume of these waste streams.

This PWA will be reevaluated in approximately 18 to 24 months, after enough time has elapsed to implement recommendations and to compare results with the baseline established in this assessment.

\section{Summary}

The waste stream categories "Other Inorganic Solid Waste" and "Empty Containers $<30$ Gallons" were described in the Source Reduction Evaluation Review And Plan (SRERP) as two of the site's major waste streams in 1990.3 The "Other Inorganic Solid Waste" waste stream was SNL/California's largest overall, contributing approximately $31 \%$ of the total waste generated on-site in 1990. The "Empty Containers <30 Gallons" waste stream was the second largest, contributing approximately $9 \%$ of the total waste generated on-site in 1990. 
The SRERP describes these waste streams as follows:

- "Other Inorganic Solid Waste" (California Waste Code 181) includes the following:

- chemically contaminated large equipment and hardware that cannot be decontaminated;

- chemically contaminated 55-gallon drums and containers larger than 30 gallons that cannot be recycled or reused;

- miscellaneous batteries;

- fluorescent light tubes;

- used toner cartridges; and

- incinerator ash.

- "Empty Containers < 30 Gallons" (California Waste Code 513) comprise glass and plastic bottles, cans, rags, and absorbent.

The data reported in the SRERP were based on the 1990 Hazardous Waste Shipment Log. ${ }^{5}$ The wastes were categorized according to California Waste Codes (CWCs) in use at that time. Since the SRERP was published, SNL/California has changed the way these wastes are categorized. In 1992, these two waste streams contributed $31 \%$ and $10 \%$, respectively, to the site overall hazardous waste stream. However, comparing this data to 1990 data for waste minimization purposes is not really useful because of the change in how Sandia now categorizes wastes. The current data will be used as a baseline for future evaluations.

Waste minimization steps that have been implemented to date are summarized below.

\section{Other Inorganic Solid Waste}

Before October 1992, burned-out fluorescent light tubes were crushed and disposed of as a hazardous waste. Now, they are placed in their original boxes and sent on a bill of lading to Mercury Technologies Corporation in Benicia, CA, for full recycling. Mercury, glass, and aluminum end caps are all recycled. This minimization effort has resulted in fluorescent light tubes being eliminated from the hazardous waste stream. The light tubes had been contributing approximately 2 to 3 tons of waste per year. The potential hazards (dust and mercury vapor) associated with crushing the tubes were also eliminated.

Some types of used laser printer toner cartridges are collected by the Materials Management and Mail Services Department (8533) and sent off-site for recycling. Since we began recycling in December 1992, 220 cartridges have been recycled for a return of $\$ 1,071$. $^{6}$

Some used batteries are now recycled. Nicad batteries are recycled by Inmetco in Ellwood City, PA, and mercury batteries are recycled by Bethlehem Apparatus in Hellertown, PA. 


\section{Empty Containers $<30$ Gallons}

Hazardous chemicals have been replaced with nonhazardous chemicals, whenever possible.

An inventory control and tracking system has been implemented for chemicals; this system allows Sandia to avoid duplication of chemicals on-site.

Containers are reused as many times as practical before disposal.

Absorbent socks (used by the Machine Shop) are washed in the parts washer and reused.

\section{Process Waste Assessment}

\section{Processes}

- Other Inorganic Solid Waste

- Empty Containers $<30$ Gallons

\section{Background}

The SNL/California SRERP identified "Other Inorganic Solid Waste" (CWC 181) and "Empty Containers <30 Gallons" (CWC 513) as major hazardous waste stream processes. ${ }^{3}$ According to the SRERP, these two waste streams accounted for approximately $40 \%$ oi the total waste generated on-site in 1990 . They were generated by the daily activities of many of the SNL/California line organizations.

Normally, PWAs are conducted on a single process that generates one or more hazardous wastes. In contrast, this PWA was done on the two listed waste streams (generated by a number of different processes) because the SRERP identified them as "processes." This report identifies as many of the components and generation mechanisms as possible in order to accomplish its two main purposes:

1. establish a new baseline for these two waste streams and

2. encourage generators to participate in reducing the volume of these waste streams.

This PWA will be reevaluated in approximately 18 to 24 months, after enough time has elapsed to implement recommendations and to compare results with the baseline established in this assessment.

Figure 1 is a site process flow diagram representing how these two waste streams are generated on-site. 


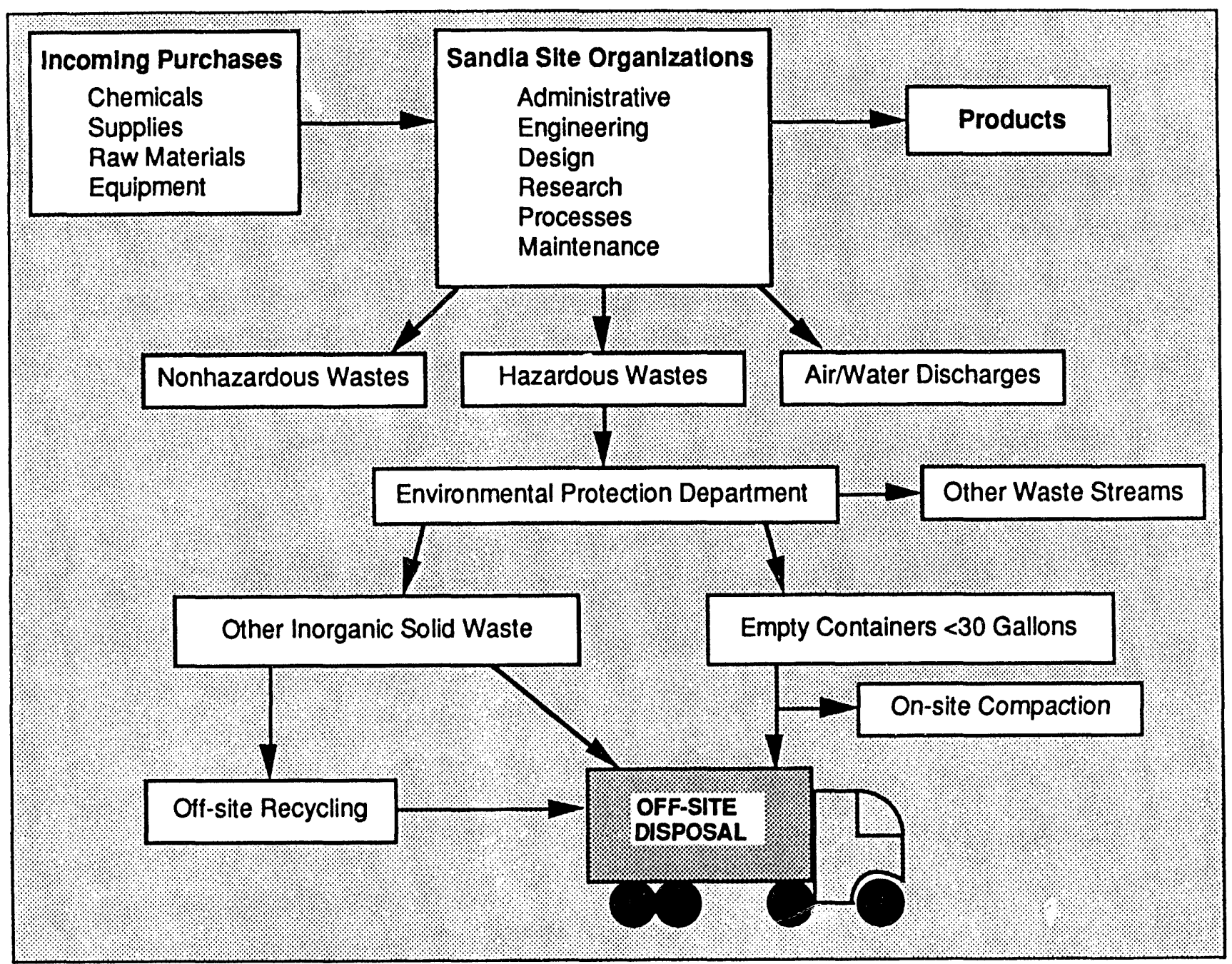

Figure 1. Site process flow for "Other Inorganic Solid Waste" and "Empty Containers <30 Gallons."

\section{Waste Characterization and Generation}

\section{Other Inorganic Solid Waste}

"Other Inorganic Solid Waste" was the largest waste stream generated at SNL/California in 1990 , contributing approximately $31 \%$ to the total volume of waste generated on-site. ${ }^{3}$ In 1990, this waste stream comprised the following:

- chemically contaminated large equipment and hardware (from research facility renovations or replacement), which cannot be decontaminated;

- 55-gallon drums and containers that can hold more than 30 gallons, which are contaminated with hazardous chemicals and cannot be recycled or reused;

- miscellaneous batteries from various types of equipment, such as calculators, cameras, pagers, cellular phones, and flashlights;

- fluorescent light tubes;

- used toner cartridges; and

- incinerator ash. 
When the SRERP was published in 1990, the major portion of the "Other Inorganic Solid Waste" stream was identified as CWC 181. However, since 1990, changes in the way $\mathrm{SNL} /$ California categorizes wastes have placed some of these wastes into different categories. These changes have made comparing some of the older data to the new data impractical. The current data will serve as a baseline for future comparisons.

Table 1 characterizes the major constituents of the "Other Inorganic Solid Waste" stream generated from January 1990 to July 1993. Based on the data in Table 1 and the total amount of hazardous waste generated on-site in $1992(165,634 \mathrm{lbs}$.$) , this waste stream was$ still one of the largest in 1992. It contributed approximately $31 \%$ to the site's overall hazardous waste output. However, a major portion of the total waste generated in 1992, came from one 25,000-lb. environmental chamber. This piece of equipment contributed more than $49 \%$ of the waste stream. Without the chamber, this waste stream would have contributed only about $15 \%$ to the site total. Also, some contaminated large equipment waste has been generated less frequently and should no longer be considered a routinely generated waste.

\section{Process Flow}

Figure 2 shows the "Other Inorganic Solid Waste" flow diagram, as described in the SRERP. It also shows how the components are segregated and categorized now.

\section{Waste Minimization}

SNL/California has made significant efforts to reduce the generation of "Other Inorganic Solid Waste." For example, in October 1992, we began a recycling program for fluorescent

Table 1. Major Constituents of the "Other Inorganic Solid Waste Stream," Generated at SNL/California from January 1990 to July 1993.

\begin{tabular}{|c|c|c|c|c|c|}
\hline \multirow[t]{2}{*}{ Hazardous Waste ID } & \multirow{2}{*}{$\begin{array}{c}\text { CWC ID } \\
\text { (1/92 to } 7 / 93)\end{array}$} & \multicolumn{4}{|c|}{ Quantity Generated } \\
\hline & & YTD 7/93 (lbs.) & 1992 (lbs.) $)^{5,7}$ & 1991 (lbs.) $)^{5,7}$ & 1990 (lbs.) $^{3}$ \\
\hline Miscellaneous Batteries & $551 / 181$ & 551 & 1,600 & 1,004 & 1,308 \\
\hline Fluorescent Light Tubesa & $551 / 0$ & 0 & 5,900 & 2,400 & 4,000 \\
\hline $\begin{array}{l}\text { Contaminated Large } \\
\text { Equipment/Hardware }\end{array}$ & $151 / 181$ & 4 & $37,150 \mathrm{~b}$ & 20,000 & $\begin{array}{r}54,000 \\
\text { (total) }\end{array}$ \\
\hline Containers $>30$ Gallons & 512 & 938 & 1,380 & 3,260 & $\begin{array}{l}\text { Combined in } \\
\text { above total. }\end{array}$ \\
\hline \multirow{2}{*}{$\begin{array}{l}\text { Miscellaneous Chemicals/ } \\
\text { Contaminated Solids, ash, } \\
\text { and toner. }\end{array}$} & $551 / 571 / 181$ & 12,000 & 5,090 & 8,151 & $\begin{array}{l}\text { Combined in } \\
\text { above total. }\end{array}$ \\
\hline & Total: & 13,493 & 51,121 & 34,815 & 59,308 \\
\hline
\end{tabular}

Note: In 1992, some materials were still categorized as CWC 181 and were changed to their new categories later.

as of 10/92, fluorescent light tubes are recycled and are not considered hazardous waste.

bOne environmental chamber (25,000 lbs.) and eight laboratory ovens (CWC 151). 5 
light tubes. They are placed in their original boxes and sent whole to Mercury Technologies Corporation in Benicia, CA, for full recycling (including the glass tubes, mercury, and aluminum end caps). Before October 1992, the light tubes were crushed and sent to Bethlehem Apparatus in Hellertown, PA, as a hazardous waste. As a result of the new process, approximately 2 to 3 tons of waste annually have been eliminated. The hazards associated with crushing the light tubes (dust, mercury vapor) also have been eliminated.

Another step SNL/California has taken to reduce this waste stream is recycling some of the used laser printer toner cartridges generated on-site. The recycling program began in December 1992. Since then, 220 cartridges have been recycled for a return of $\$ 1,071$. Additionally, by not sending these 220 cartridges to a landfill, approximately $64 \mathrm{ft}^{3}$ of

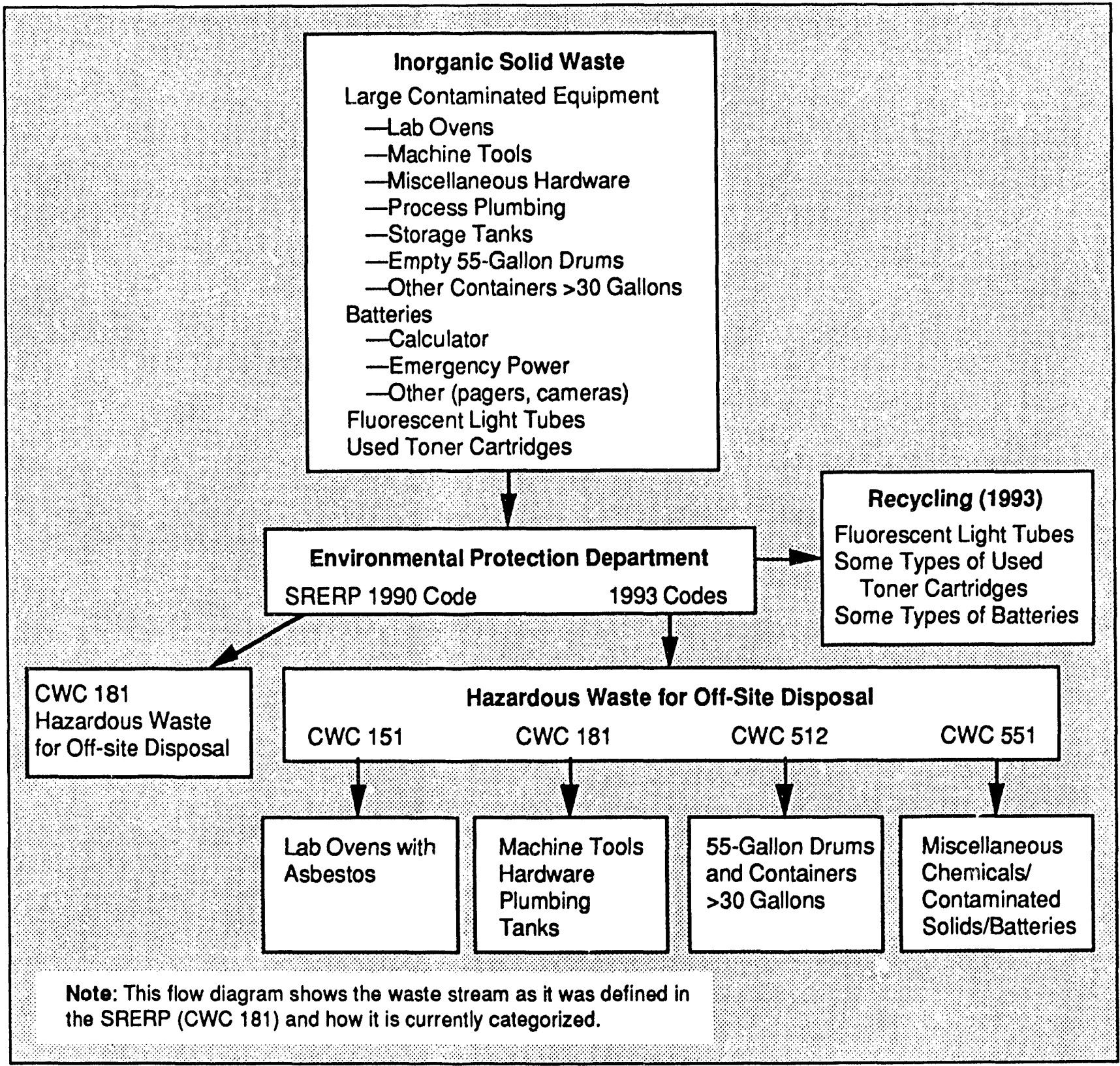

Figure 2. "Other Inorganic Solid Waste" flow diagram. 
landfill space have been saved. 6 The recyclable cartridges are collected from various locations around the site by the Materials Management and Mail Services Department (8533) and are sent to an off-site vendor for recycling. Some types of cartridges are still treated as hazardous waste because of the hazardous materials in the toner. Others are sent to a municipal landfill for disposal because they cannot be recycled.

Finally, SNL/California has begun a program to collect and segregate some batteries for off-site recycling. Mercury batteries are recycled by Bethlehem Apparatus in Hellertown, PA. Nicad batteries are recycled by Inmetco in Ellwood City, PA.

\section{Empty Containers $<30$ Gallons}

According to the SRERP data, "Empty Containers $<30$ Gallons" (CWC 513) was the site's second largest waste stream in 1990, accounting for approximately $9 \%$ of the total hazardous waste generated. It comprised glass and plastic bottles, cans, rags, and absorbent. ${ }^{3}$

Sandia personnel generate this waste stream by using many different chemicals. When they dispose of these containers, the Environmental Protection Department combines any chemical wastes left in the containers with similar wastes in 55-gallon drums. All empty containers are then compacted into 55-gallon drums.

Currently, this waste stream comprises only glass and plastic bottles, and cans (not rags and absorbent); however, it is still categorized as CWC 513. Also, the rags and absorbent still are compacted in the same drums as the CWC 513 waste, but they now are coded as CWC 551. Additionally, Environmental Protection Department separates the categories into two classes based on their British thermal unit (BTU) value. The plastic containers, rags/wipes, and small amounts of absorbent are classified as high BTU, flammable compactible. The glass bottles, cans, and larger quantities of absorbent are classified as low BTU, flammable compactible.

Because this waste is categorized and segregated differently now than it was in 1990, a direct correlation between the volumes generated in 1990 and those generated now may not be accurate. Therefore, although we have implemented measures to reduce the amount of this waste generated, we cannot accurately determine the amount of reduction.

Table 2 lists the quantity of "Empty Containers <30 Gallons" generated from January 1990 to July 1993. The data available for 1992 show that this waste stream contributed approximately $10 \%$ to the total amount of hazardous waste $(165,634 \mathrm{lbs}$.) generated on-site. This data should not be compared to data from 1990 and 1991 because of the category changes. However, the current data should provide a baseline for future comparison.

Table 2. Amount of the Empty Containers <30 Gallons Waste Stream Generated at SNL/California (January 1, 1992 to June 30, 1993, and in 1990).

\begin{tabular}{|l|c|c|c|c|c|}
\hline Hazardous Waste ID & CWC ID & \multicolumn{4}{|c|}{ Quantity Generated } \\
\cline { 3 - 6 } & $(1 / 92$ to 7/93) & YTD 7/93 (lbs.) $)^{5,7}$ & 1992 (lbs.) $^{5,7}$ & 1991 (lbs.) $^{5,7}$ & 1990 (lbs.) $^{3}$ \\
\hline $\begin{array}{l}\text { Empty Containers } \\
<30 \text { Gallons }\end{array}$ & $513 / 551$ & 8,074 & 17,096 & 16,200 & 18,000 \\
\hline
\end{tabular}

"Includes rags and absorbents. 


\section{Process Flow}

Figure 3 shows the process flow of "Empty Containers $<30$ Gallons" at SNL/California. It also shows the waste stream as it was described in the SRERP (1990) and how the waste stream is categorized now.

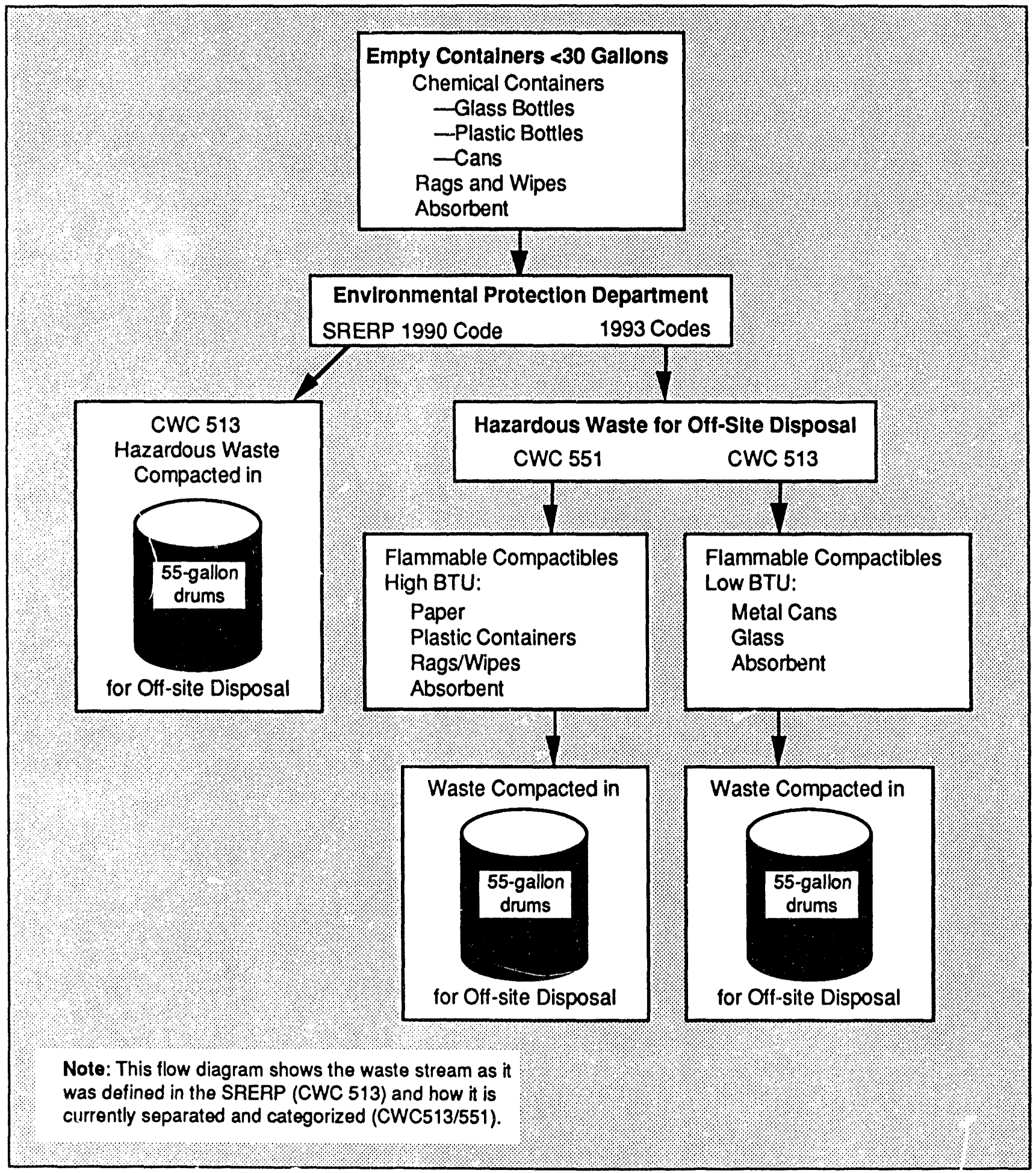

Figure 3. "Empty Containers < 30 Gailons" flow diagram. 


\section{Waste Minimization}

The waste stream, "Empty Containers $<30$ Gallons," is one of the most difficult to minimize. However, SNL/California has taken steps to reduce the amounts generated onsite, as follows:

- Empty containers are compacted to reduce volume (as permitted in Part B).

- Containers are reused as many times as practical before they are disposed of as hazardous waste.

- Hazardous chemicals are being replaced with nonhazardous chemicals, which helps reduce waste container generation; for example, the use of nonhazardous, water-based paints instead of oil-based paints allows the empty paint containers to be washed out with water and reused or disposed of as nonhazardous waste.

- An inventory control and tracking system helps avoid duplication of chemicals already on-site, thereby reducing the sources of the waste stream.

- The Machine Shop Facility has reduced its generation of waste absorbent, which was categorized in this waste stream in 1990 (and now is in CWC 551); absorbent socks now used to absorb machine oils are washed in the parts washer and reused two or three times before they must be replaced. ${ }^{8}$ This procedure minimizes the generation of the waste and saves on raw materials and disposal costs.

Some generators triple-rinse their containers ( $<5$ gallons), retain the rinsate as hazardous waste, and dispose of the containers as nonhazardous waste.

\section{Material Balances}

These two waste streams are generated by a number of different sources, whose characteristics vary widely. Performing a material balance on either of these waste streams is not feasible or practical.

\section{Recommendations}

\section{Other Inorganic Solid Waste}

"Other Inorganic Solid Waste" (CWC 181) has been the site's largest waste stream. However, it is difficult to minimize because of the many waste generators. Successfully minimizing this waste will require the support of all the generators. Recommendations include the following:

- Contaminated large equipment contributes the largest volume to this waste stream, even though it is not a routinely generated waste. Facility owners should be made aware of the importance of reducing this waste. Through 
careful initial planning, they may be able to develop their processes and procedures so that the waste is not generated at all.

- Apparently, more used batteries have been generated on-site (based on the available data) since 1990. Battery usage should be evaluated to determine if some batteries can be replaced with rechargeable ones, or if their lives can be extended through type or procedural changes.

\section{Empty Containers $<30$ Gallons}

This waste stream is also difficult to minimize because such a wide variety of chemicals is involved and because numerous generators contribute to it. Source reduction is the most desirable approach to reducing the volume of this waste stream.

Recommendations include the following:

- Continue waste minimization training programs for the waste generators and request their support in reducing the quantities of the containers they generate.

- Evaluate the existing chemicals used on-site to determine if opportunities exist to minimize or restrict the numbers and types purchased. In some cases, one chemical may be used instead of two to achieve the same end result; thus, the amount of chemicals and the number of waste containers generated on-site would be minimized.

- Continue to evaluate opportunities to replace hazardous chemicals with nnnhazardous chemicals.

- Containers that hold less than 5 gallons and contain water-soluble or aqueous chemicals may be rinsed (the rinsate is retained as hazardous waste) and then discarded in the municipal trash. This form of rinsing is not regulated by the Cal/EPA Permit-by-Rule Program. (Note: Larger containers, which can hold more than 5 gallons, cannot be rinsed without Permit by Rule.9)

- Weigh all materials received by the Hazardous Waste Facility. Weighing all the components in this waste stream would help identify the major components and define specific minimization efforts.

- Formalize the Chemical Exchange Program to document chemical quantities diverted from hazardous waste disposal. 


\section{References}

1. U.S. Department of Energy, Order 5400.1, General Environmental Protection Program (November 9, 1988).

2. U.S. DOE, Order 5400.3, Hazardous and Radioactive Mixed Waste Program (February 22, 1989).

3. SNL/California, Process Waste Assessment Plan (June 1993).

4. SNL/California, Source Reduction Evaluation Review and Plan (September 1, 1991).

5. SNL/California, Hazardous Waste Shipment $\log (1990,1992$, and 1993).

6. Lollie Nunez, SNL/California Material Management Department, Memo: Toner Cartridge Recycling Program (September 7, 1993).

7. SNL/California, Hazardous Waste Container Log (1992 and 1993).

8. And. Cardiel, SNL/California Machine Shop, private communication (1993).

9. Gwyn Faulkner, SNL/California Environmental Protection Department, private communication (1993). 


\section{UNLIMITED RELEASE}

\section{INITIAL DISTRIBUTION}

U.S. Department of Energy (2)

Albuquerque Operations Office

Attn.: T. Pietrok, KAO

M. Williams, WMD

P.O. Box 5400

Albuquerque, NM 87115

MS1305, J. D. Fish, Org. 7576

MS1305, R. Davis, Org. 7576

MS9001, J. C. Crawford, Org. 8000

Attn.: D. L. Crawford, 1900

G. E. Ives, 5200

J. B. Wright, 5300

M. E. John, 8100

R. J. Detry, 8200

W. J. McLean, 8300

L. A. Hiles, 8400

P. E. Brewer, 8500

L. A. West, 8600

R. C. Wayne, 8700

MS9133, A. Cardiel, Org. 8284-1

MS9707, C. L. Knapp, Org. 8415

MS9281, L. Nunez, Org. 8533

MS9021, K. W. Gordon, Org. 8535

MS9222, E. Dolstra, Org. 8642

MS9222, G. Faulkner, Org. 8642

MS9222, R. Garcia, Org. 8642

MS9222, A. J. Johnson-Duarte, Org. 8642

MS9222, K. Lloyd, Org. 8642

MS9222, D. McMaster, Org. 8642

MS9222, D. A. Nissen, Org. 8642

MS9222, N. M. Phillips, Org. 8642 (15)

MS9222, S. J. Raubfogel, Org. 8642

MS9222, K. K. Shepodd . Org. 8642

MS9021, Technical Communications for OSTI, Org. 8535 (10)

MS9021, Technical Communications/Technical Library Processes

MS0899, Technical Library Processes Department, Org. 7141 (4)

MS9018, Central Technical Files, Org. 8523-2 (3) 
11
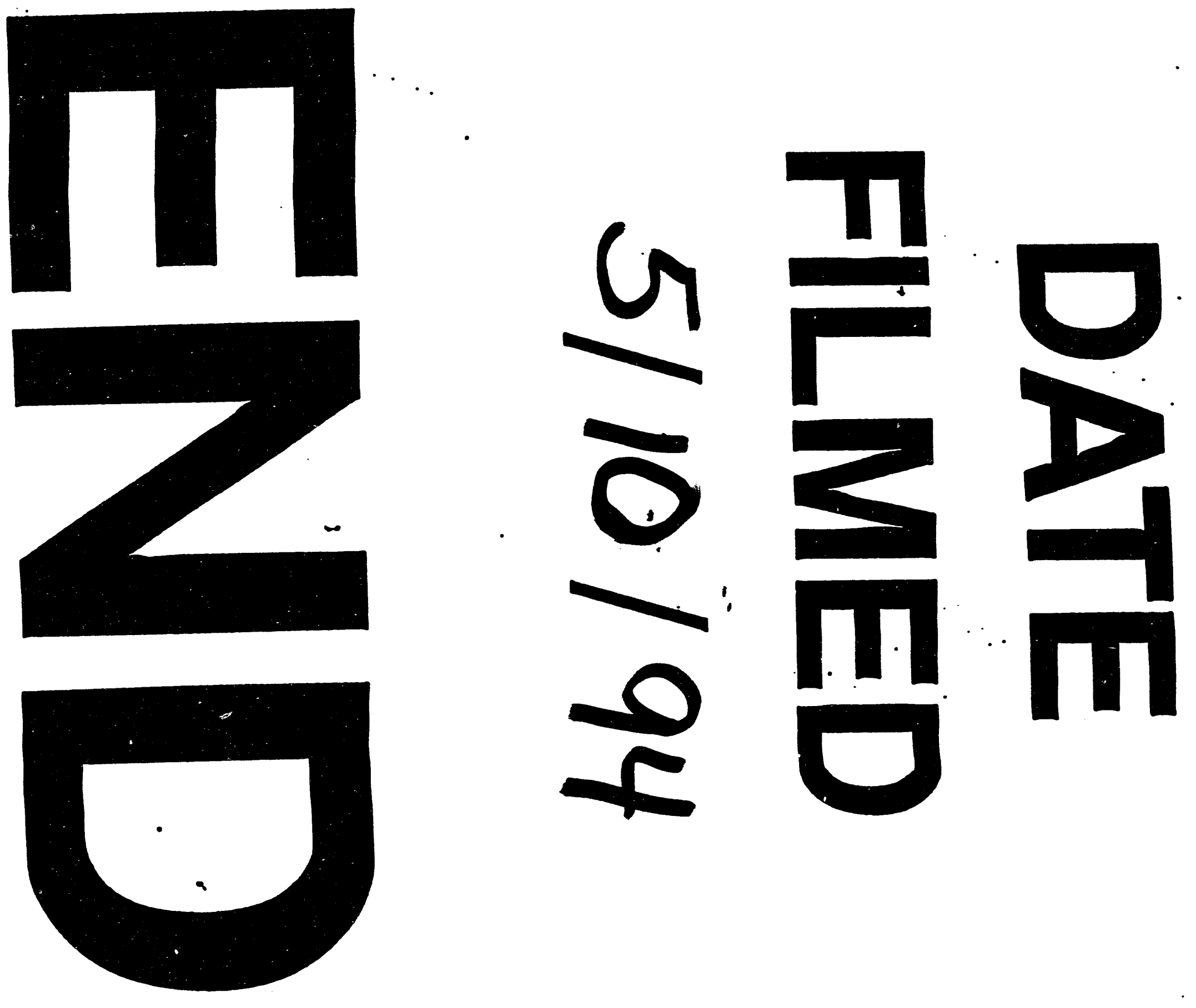
$$
\text { m }
$$ 